\title{
The Study of the Strength Properties of Galvanized Iron (GI) Fiber Reinforced Concrete
}

\author{
Sristi Das Gupta*, Md Shah Newaz Aftab Chayon, Chaity Kamaka, Hasan Mohammad Zakaria \\ Department of Civil Engineering, Ahsanullah University of Science and Technology, BANGLADESH \\ 41 \& 142, Love Road, Tejgaon Industrial Area, Dhaka-1208 \\ *Corresponding authors: sristi.ce@aust.edu
}

SUBMITTED 14 June 2010 REVISED 4 August 2020 ACCEPTED 21 August 2020

\begin{abstract}
The use of concrete with randomly distributed metallic or non-metallic fiber is now prominent in concrete engineering and metallic fiber has been reported to have a better contribution to concrete mechanical properties. The utilization of locally available galvanized iron or metallic fiber as a bridging material which is a new technique in Bangladesh has the ability to surprisingly improve concrete physical properties. This research was, therefore, conducted to compare the concrete performance of GI fiber and steel fiber using previous literature as well as the suitability of GI fiber as a supplant to steel fiber in the concrete industry. This was achieved through the evaluation of the compression, tension, and brittleness of concrete with 'Galvanized Iron' fiber using several cutting lengths of $20 \mathrm{~mm}$ and $40 \mathrm{~mm}$ with multiple mix proportions including $1.0 \%, 1.5 \%, 2.0 \%$, and $2.5 \%$ by volume of the concrete. The results showed the fiber with a large cut length of $40 \mathrm{~mm}$ and proportion lesser than $2.5 \%$ performed well than $20 \mathrm{~mm}$ with proportion $>2 \%$ in reference to the plain concrete. Moreover, the incorporation of a $2.0 \%$ proportion of galvanized iron fiber with $40 \mathrm{~mm}$ length was observed to have exhibited crowning increment for both concrete compression and tension by $16.1 \%$ and $89.2 \%$ correspondingly contrasted to the control specimen. A further increase in the percent of fiber content $>2 \%$ led to a reduction in the compression and tension for both $20 \mathrm{~mm}$ and $40 \mathrm{~mm}$ lengths while a significant reduction in brittleness for galvanized iron fiber reinforced concrete was observed in contrast to the control specimen. Furthermore, the inclusion of $1.0 \%-2.5 \%$ GI fiber with a $40 \mathrm{~mm}$ length reduced concrete brittleness by $56.9 \%-65.5 \%$ in comparison with the control specimen. Therefore, the inclusion of galvanized iron (metallic) to enhance the physical properties of concrete was deduced to be one of the startling stratagems.
\end{abstract}

KEYWORDS Metallic Fiber Reinforced Concrete; Galvanized Iron (GI); Compression; Tension; Brittleness.

(c) The Author(s) 2020. This article is distributed under a Creative Commons Attribution-Share Alike 4.0 International license.

\section{INTRODUCTION}

Building construction materials such as concrete which is produced through a carefully proportioned mixture of cement, sand, gravel or other aggregates, and water and hardened in different forms and dimensions for the specified structure. The materials are amalgamated to ensure the voids within the aggregates are satiated to produce a consistent dense concrete. It is important to note that concrete has been the foremost widely used construction material throughout the planet with those made using hydraulic cement observed to be having certain characteristics while plain and unreinforced concrete is a friable material with a picayune strain capacity (Islam, G. M. S, et al., 2016). Concrete is relatively sturdy in compression but languid in tension and tends to be fragile. This, therefore, makes it important from the engineering perspective and there has been a continuing effort to upgrade its performance.

The greatest abridgment for concrete is the lack of ductility and the improvement of this aspect is a prime concern for civil engineers. This has, therefore, led to a considerable number of studies incorporating different fibers such as steel, jute, glass, and polymer in concrete (Nemati, K. M, 2013). The concept is generally known as the Fiber Reinforced Concrete (FRC) and has been found to be one of the foremost promising new construction materials due to its enhanced ductility and decreased brittleness (Rouhi, J, et al., 2011). The inclusion of the fibers also modifies the behavior of the fiber-matrix 
composite after it has cracked, thereby, upgrading its toughness.

The real contribution of the fibers is to extend the toughness of the concrete (Sivakumar. A, et al., 2007) which has been described to be an area under a load-deflection curve. This is due to the fact that plain concretes fail suddenly once the greatest strength is surpassed while fiber ferroconcrete continues under considerable loads even at deflections considered more than the fracture deflection in plain concrete. This means fiber-reinforced concrete is in a position to sustain load or strain much greater than plain concrete (Kim, J. S, et al., 2017).

Fiber ferroconcrete is also generally defined as a material made with hydraulic cement, aggregate, and incorporating discrete discontinuous fiber (ACI 544.4R-88, 1999). Galvanized steel wire or iron (GI) formed from zinc-plated steel is presently used as a reinforcement to improve concrete properties mainly due to the ability of the protective layer of zinc to inhibit corrosion. Several studies have been conducted to investigate the suitability of GI fibers as an alternative to steel or hybrid fibers. This is important considering the fact that steel fiber is the most prominent metallic fiber with the ability to augment concrete properties but it is expensive to be used in Bangladesh due to additional cost attached to its unavailability in the local market. Studies have also been conducted to determine the substitute reinforcing material to emulate steel fiber in improving the mechanical properties of concrete at a lower cost. Some others also focused on using different mix proportions of steel fiber to determine their effectiveness but there is no significant research on the use of GI fiber with different cutting length and at several mix proportions.

This means it is considerably important to determine the influence of the effective utilization of galvanized iron (GI) fiber to produce ennobled concrete. Therefore, the foremost objective of the study was to develop galvanized iron (GI) fiber reinforce concrete composites, and determine the suitable length and content (volume fraction) of fibers based on concrete mechanical behavior.

\section{MATERIALS AND METHODS}

\subsection{Portland Cement}

Ordinary hydraulic Cement containing 95-100\% and $0-5 \%$ of clinker and gypsum respectively at a precise gravity of 3.12 was used in this study.

\subsection{Coarse and Fine Aggregates}

Sylhet sand was utilized as the fine aggregate while crushed stone chips were treated as the coarse aggregate using a grading consistent with ASTM C33. The aggregates were collected from Sylhet and their physical properties are presented in Table 1.

Table 1. Physical characteristics of aggregates

\begin{tabular}{lcl}
\hline Property & Sand & $\begin{array}{l}\text { Stone } \\
\text { Chips }\end{array}$ \\
\hline Bulk Specific Gravity (OD Basis) & 2.54 & 2.66 \\
Absorption Capacity (\%) & 1.34 & 0.69 \\
Fineness Modulus (FM) & 2.62 & - \\
Dry Rodded Unit Weight $\left(\mathrm{kg} / \mathrm{m}^{3}\right)$ & 1590 & 1550 \\
\hline
\end{tabular}

\subsection{Galvanized Iron Fiber}

Galvanized iron (GI) fiber has a circular section with the diameters varying from $0.37 \mathrm{~mm}$ to 5 $\mathrm{mm}$ but those with $1 \mathrm{~mm}$ diameter were used in this study. According to the manufacturers, the materials are resistant to high temperature and corrosion and also provide high strength considering the properties shown in Table 2. Two different cut lengths including 20 and $40 \mathrm{~mm}$ as presented in Fig. 2 were used in this study at different volumetric percentages of $1 \%, 1.5 \%, 2 \%$, and $2.5 \%$ in the concrete mixture. 


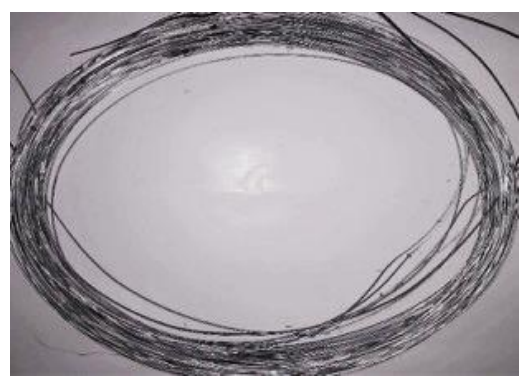

(a)

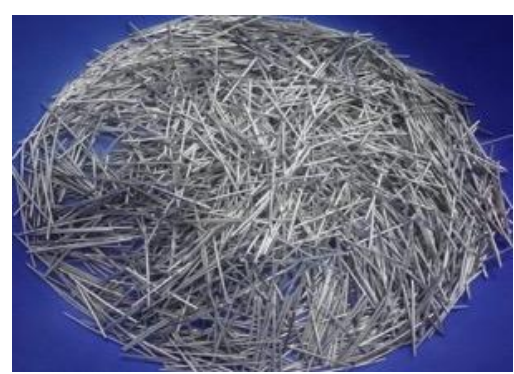

(b)

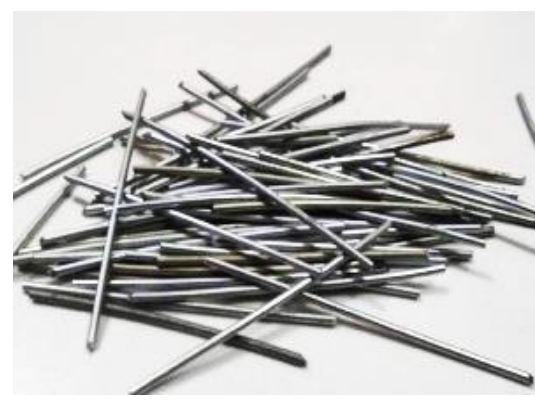

(c)

Figure 1. (a) Galvanized iron (GI) (b) GI with $20 \mathrm{~mm}$ length (c) GI with $40 \mathrm{~mm}$ length

Table 2. Characteristics of Galvanized iron (GI) fiber employed in this study (American Galvanizers Association)

\begin{tabular}{ll}
\hline GI Fiber & Feature \\
\hline Cutting Length $(\mathrm{mm})$ & 20 \\
Cutting Length $(\mathrm{mm})$ & 40 \\
Diameter $(\mathrm{mm})$ & 1 \\
Aspect Ratio $(l / d)$ & 20 \\
Aspect Ratio $(l / d)$ & 40 \\
Density $(\mathrm{kg} / \mathrm{m} 3)$ & 6000 \\
Tensile Strength $(\mathrm{MPa})$ & 250 \\
Color & Silver \\
Elastic Modulus $(\mathrm{GPa})$ & 6.0 \\
\hline
\end{tabular}

\subsection{Concrete Mix Proportions}

Trial mixtures were prepared to obtain the targeted strength of $35 \mathrm{MPa}$ at 28 days with a target slump value of 75-100 mm. The concrete mix was designed according to the standards of the American Concrete Institute (ACI 211, 2009). The fibers added reduced the slump value due to the interweaved arrangement of fibers in the concrete matrix. Therefore, additional water was needed compare to control concrete to keep the slump within the mix design range. The detailed mix proportions of the constituent materials, with the SSD condition where applicable, to produce the concretes used in this study are presented in Table 3.

\subsection{Concrete Mixing, Casting, and Curing}

The concrete mixture was prepared with different parameters including the length and volume fraction of the iron fiber content while the cut lengths of the fiber were 20 and $40 \mathrm{~mm}$ at $1 \%, 1.5 \%, 2 \%$, and $2.5 \%$ proportion. The fibers were truncated to the desired length using a wire cutting machine while the concrete was prepared through a machine mixer by considering a 50liter volume for each trial blend. The process involved mixing the appropriate quantity of coarse aggregates, fine aggregates, and cement followed by the inclusion of the iron fibers to obtain congruous distribution in every part of the concrete after which water was added with four minutes of vigorous mixing to achieve consistency. A slump cone was used to measure the workability of the mixture while a $150 \mathrm{~mm}$ cube specimen was set and placed in a circumambient temperature for 24 hours to conduct laboratory strength tests. Subsequently, the specimens were extracted from the mold and placed in a curing tank to determine the strength at 7 and 28 days. 
Table 3. Mixing composition of concrete utilized in laboratory works (Galvanized iron)

$\begin{array}{llllll}\text { Proportion } & \begin{array}{l}\text { Water } \\ \left(\mathrm{kg} / \mathrm{m}^{3}\right)\end{array} & \begin{array}{l}\text { Cement } \\ \left(\mathrm{kg} / \mathrm{m}^{3}\right)\end{array} & \begin{array}{l}\mathrm{CA}\left(\mathrm{kg} / \mathrm{m}^{3}\right) \\ {[\mathrm{SSD}]}\end{array} & \begin{array}{l}\mathrm{FA}\left(\mathrm{kg} / \mathrm{m}^{3}\right) \\ {[\mathrm{SSD}]}\end{array} & \mathrm{GI}\left(\mathrm{kg} / \mathrm{m}^{3}\right) \\ \begin{array}{l}\text { Control Concrete } \\ \text { GIF0(0.0\%) }\end{array} & 215 & 566 & 999 & 565 & 0.0 \\ & & & & & \\ \text { Galvanized Iron (20 mm) } & 218 & 566 & 999 & 565 & 23.45 \\ \text { GIF1 (1.0\%) } & 219 & 566 & 999 & 565 & 35.17 \\ \text { GIF2 (1.5\%) } & 223 & 566 & 999 & 565 & 46.90 \\ \text { GIF3 (2.0\%) } & 225 & 566 & 999 & 565 & 58.63 \\ \text { GIF4 (2.5\%) } & & & & & \\ & & & & & \\ \text { Galvanized Iron (40 mm) } & 217 & 566 & 999 & 565 & 23.45 \\ \text { GIF5 (1.0\%) } & 220 & 566 & 999 & 565 & 35.17 \\ \text { GIF6 (1.5\%) } & 223 & 566 & 999 & 565 & 46.90 \\ \text { GIF7 (2.0\%) } & 224 & 566 & 999 & 565 & 58.63 \\ \text { GIF8 (2.5\%) } & & & & \end{array}$

\subsection{Compression Test}

The compression of the concrete was tested using EN 12390-3 (2009). The compressive strength has been considered the most prominent feature of concrete compared to other physical properties due to its structural significance and the provision of a limpid repercussion on how the increment of fiber proportions influence the concrete strength. Moreover, the load was implemented with a strain rate of $1.5 \mathrm{~mm} / \mathrm{min}$ up to the period the specimens reached their fracture point. The highest load received by the concrete specimen throughout the test was inscribed. The experimental set up is, therefore, shown in the following Figure 2.

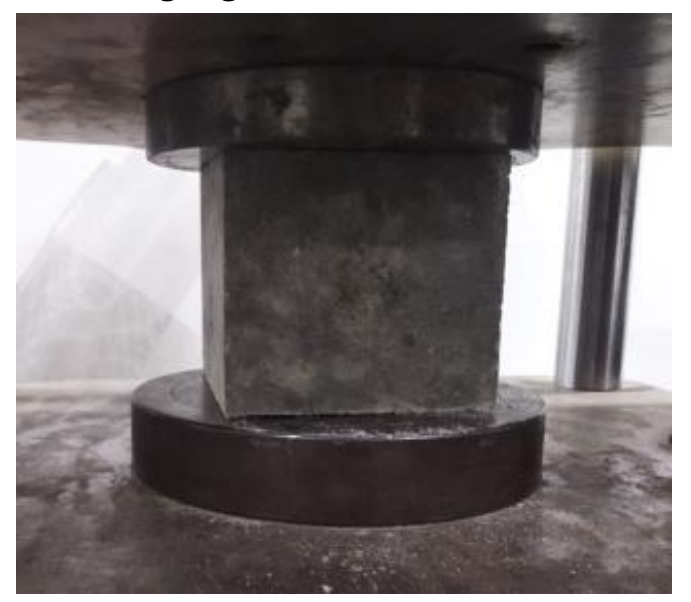

Figure 2. Laboratory arrangement for compression test.

\subsection{Tensile Strength Testing}

The friableness and modicum tensile strength of concrete make it callow to flounder with the direct tension. Therefore, assessing concrete tension is imperative to ascertain the load required for fracture through the use of a splitting experiment in accordance with the EN 12390-6 (2000). The tensile strength was, however, measured using Equation (1)

$f_{c t}=2 F / \pi L d$

where $f_{c t}$ is the tensile strength in $\mathrm{N} / \mathrm{mm}^{2}, F$ is the maximum load in Newtons $(\mathrm{N}), L$ is the length of the specimen in millimeters ( $\mathrm{mm})$, and $d$ is the size of a designated cross-section in millimeters (mm).

\section{RESULT AND DISCUSSION}

\subsection{Compressive Strength}

Compressive strength is the most fundamental property of concrete due to its main function of withstanding compressive stress. The behavior of concrete under compression load due to the utilization of galvanized Iron metallic fiber is presented in Figures 3 and 4. Meanwhile, the results presented in Table 4 showed the integration of galvanized iron fiber in concrete enhanced the compressive strength. 
Table 4. Experimental outcomes of concrete compression

\begin{tabular}{l|llllll}
\hline $\begin{array}{l}\text { Length } \\
(\mathrm{mm})\end{array}$ & $\begin{array}{l}\text { Concrete } \\
\text { Composition }\end{array}$ & $\begin{array}{l}\text { Compressive } \\
\text { strength at 7 } \\
\text { days (MPa) }\end{array}$ & $\begin{array}{l}\text { Compressive } \\
\text { strength at 28 } \\
\text { days (mpa) }\end{array}$ & $\begin{array}{l}\text { 28 days } \\
\text { strength } \\
\text { increment (\%) }\end{array}$ & $\begin{array}{l}\text { Steel } \\
\text { Fiber* }\end{array}$ & $\begin{array}{l}\text { Compressive } \\
\text { strength at 28 days } \\
(\mathrm{MPa})^{* *}\end{array}$ \\
\hline- & Control concrete & 21.023 & 36.5 & - & 0 & 33.4 \\
20 & GIF1 & 23.12 & 36.58 & 0.2 & $0.5 \%$ & 37.83 \\
& GIF2 & 24.06 & 37.24 & 1.8 & $1.0 \%$ & 43.74 \\
& GIF3 & 24.83 & 37.79 & 3.5 & $1.5 \%$ & 48.03 \\
& GIF4 & 23.64 & 36.91 & 1.1 & - & - \\
40 & GIF5 & 24.70 & 39.92 & 9.3 & - & - \\
& GIF6 & 25.43 & 40.86 & 11.9 & - & - \\
& GIF7 & 26.67 & 42.35 & 16.1 & - & - \\
& GIF8 & 26.13 & 41.52 & 13.8 & - & - \\
\hline
\end{tabular}

* Joshi A, et.al; 2016

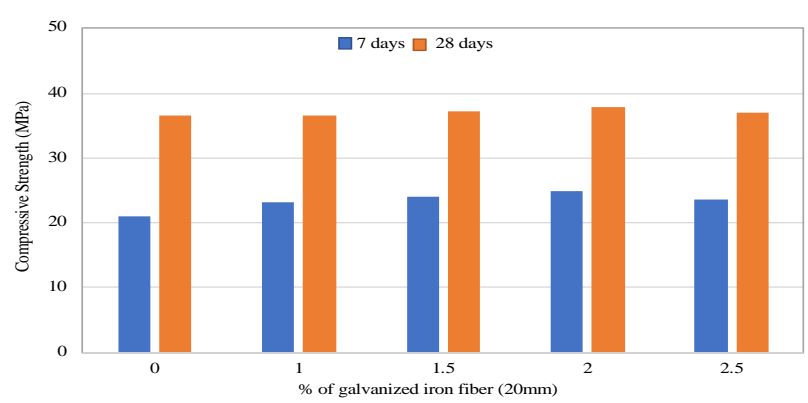

(a)

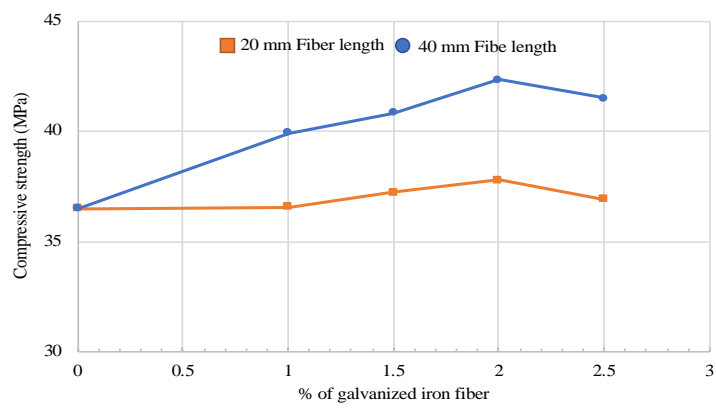

(c)

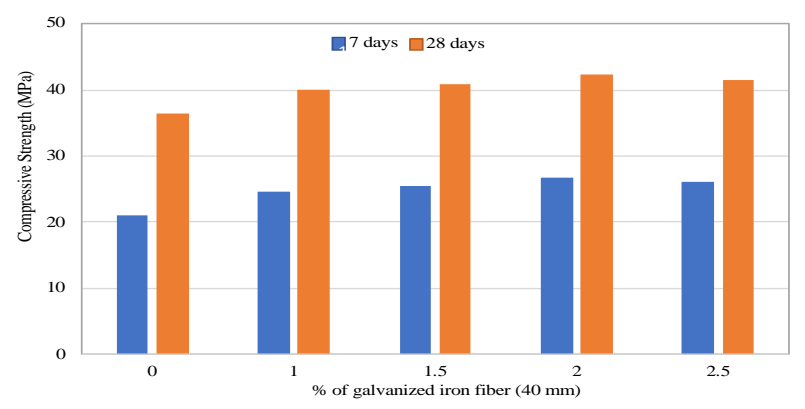

(b)

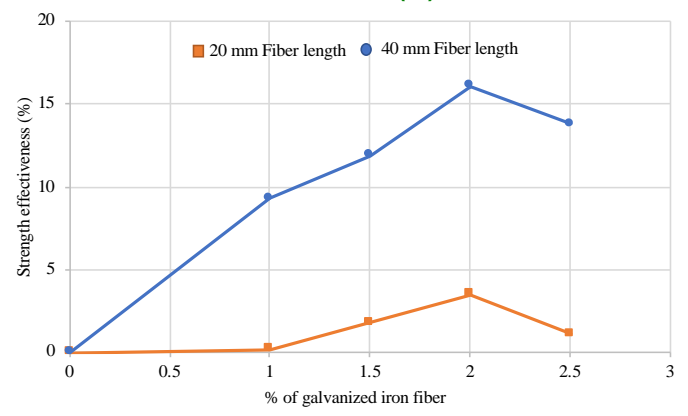

(d)

Figure 3. Change in the compressive strength of concrete at different fiber proportions (a) 20 mm length of Galvanized Iron (b) $40 \mathrm{~mm}$ length of Galvanized Iron (c) the comparison between compression for $20 \mathrm{~mm}$ and $40 \mathrm{~mm}$ length (d) comparison between the strength improvement between $20 \mathrm{~mm}$ and $40 \mathrm{~mm}$ length.

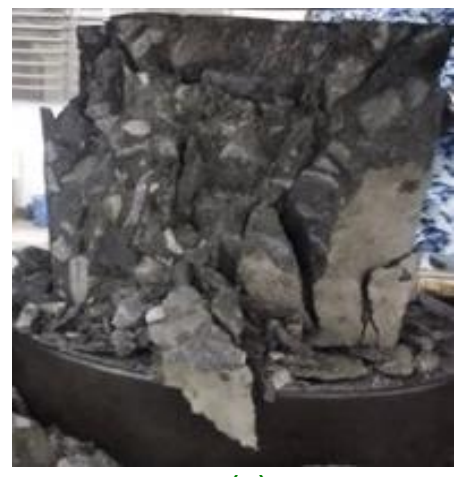

(a)

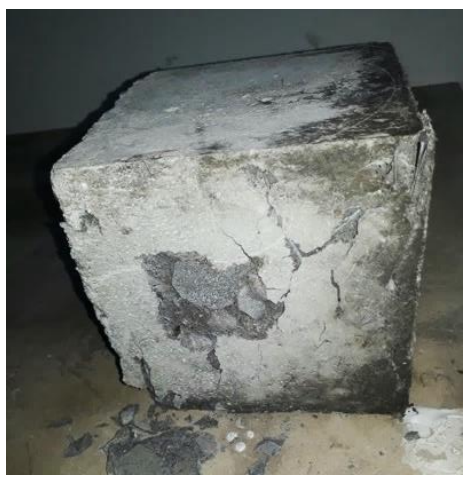

(b)

Figure 4. Concrete cube after compression test (a) Control specimen (b) GIF (1.5\%). 
Figures $3 \mathrm{a}$ and $3 \mathrm{~b}$ compare the compressive strengths on the 7th and 28th day for $20 \mathrm{~mm}$ and $40 \mathrm{~mm}$ fibers respectively and the values were observed to have aggravated up to $2 \%$ GI fiber and later reduced as the proportion increased. This was associated with the confining effect of fibers in the concrete matrix which holds the materials together. Meanwhile, this effect depends mainly on the difficulty in controlling the orientation of fibers due to its random distribution in the concrete matrix. Figure 4, however, shows the holding capacity of GI fiber to be lucid with the increment in the strength of the reinforced concrete found in the range of $0.2 \%$ to $3.5 \%$ for $20 \mathrm{~mm}$ length and $9.3 \%$ to $16.1 \%$ for $40 \mathrm{~mm}$. A slight decrease was observed in the two specimens for $2.5 \%$ proportion and this Is associated with the high dosage of fiber which affects the concrete's cohesiveness. The best result was, however, recorded at $2 \%$ proportion with $40 \mathrm{~mm}$ length as observed with the $16.1 \%$ increment in the compressive strength of the concrete. This is in agreement with the findings of previous research by Joshi et al [16] that it is possible to increase the compressive strength of concrete within a range of $13.8 \%$ to $43.8 \%$ by incorporating steel fibers.

\subsection{Tensile Strength}

Split tensile strength is the ability of concrete to withstand tension with the effect of the GI fiber incorporated determined using a split tensile test and the results obtained are presented in Table 5 and the changes recorded are demonstrated in Figure 5.

The incorporation of GI fibers was observed to have increased the split tensile strength of the reinforced concrete compared to the control specimen. Figure $5(\mathrm{~d})$ represents the effectiveness of the splitting tensile strength for the specimens at 28 days with the galvanized Iron fiber reinforced concrete observed to have increased significantly compared to the plain concrete. Moreover, the splitting tensile strength of the reinforced concrete was found to have increased in a range of $36.6 \%$ to $67.6 \%$ for $20 \mathrm{~mm}$ length as the fiber content increased while $40 \mathrm{~mm}$ length was observed to have shown a better performance with $70 \%$ to $89.2 \%$.

Table 5. Experimental outcomes of concrete compression

\begin{tabular}{|c|c|c|c|c|c|c|}
\hline $\begin{array}{l}\text { Length } \\
(\mathrm{mm})\end{array}$ & $\begin{array}{l}\text { Concrete } \\
\text { Composition }\end{array}$ & $\begin{array}{l}\text { Tensile Splitting } \\
\text { Strength at } 7 \\
\text { Days (MPa) }\end{array}$ & $\begin{array}{l}\text { Tensile Splitting } \\
\text { Strength at } 28 \\
\text { days (MPa) }\end{array}$ & $\begin{array}{l}28 \text { days } \\
\text { Strength } \\
\text { Increment (\%) }\end{array}$ & $\begin{array}{l}\text { Steel } \\
\text { Fiber* }\end{array}$ & $\begin{array}{l}\text { Tensile splitting } \\
\text { Strength at } 28 \text { days } \\
(\mathrm{MPa})^{*}\end{array}$ \\
\hline- & $\begin{array}{l}\text { Control } \\
\text { Concrete }\end{array}$ & 1.17 & 2.13 & - & 0 & 2.67 \\
\hline \multirow[t]{4}{*}{20} & GIF1 & 1.39 & 2.91 & 36.6 & $0.5 \%$ & 3.34 \\
\hline & GIF2 & 1.97 & 3.13 & 46.9 & $1.0 \%$ & 3.83 \\
\hline & GIF3 & 2.52 & 3.57 & 67.6 & $1.5 \%$ & 4.62 \\
\hline & GIF4 & 1.49 & 3.04 & 42.7 & - & - \\
\hline \multirow[t]{4}{*}{40} & GIF5 & 1.70 & 3.62 & 70 & - & - \\
\hline & GIF6 & 2.09 & 3.93 & 84.5 & - & - \\
\hline & GIF7 & 2.79 & 4.03 & 89.2 & - & - \\
\hline & GIF8 & 2.32 & 3.97 & 86.4 & - & - \\
\hline
\end{tabular}

*Joshi A, et.al; 2016 


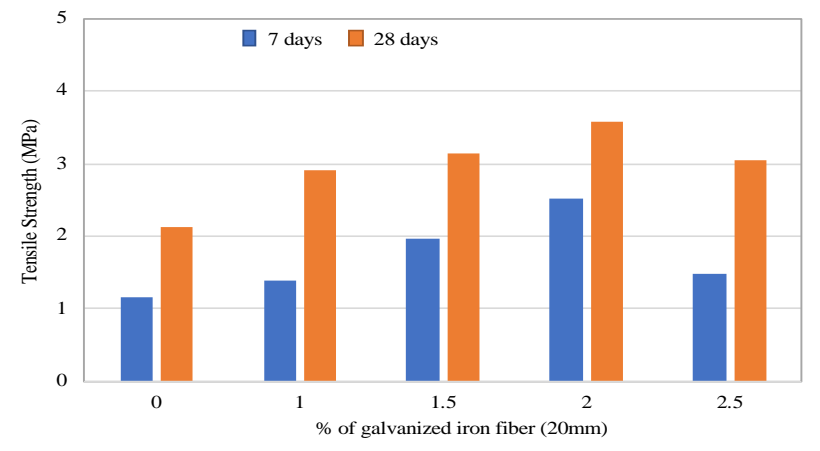

(a)

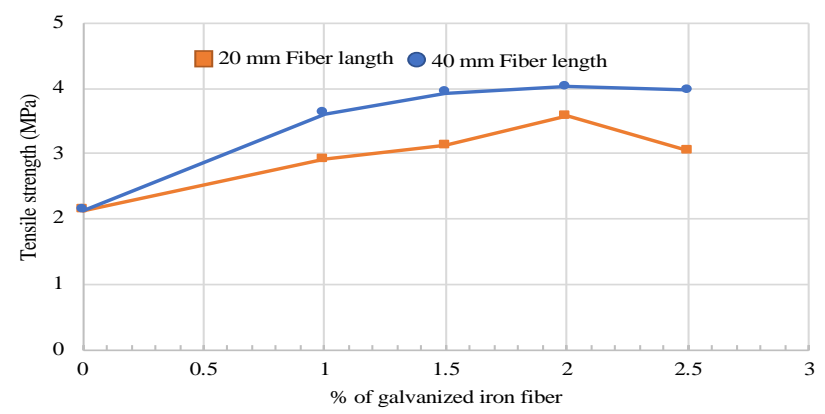

(c)

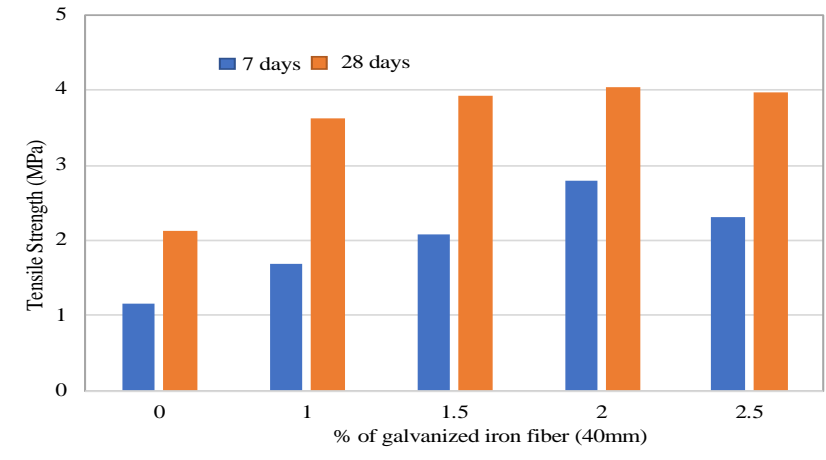

(b)

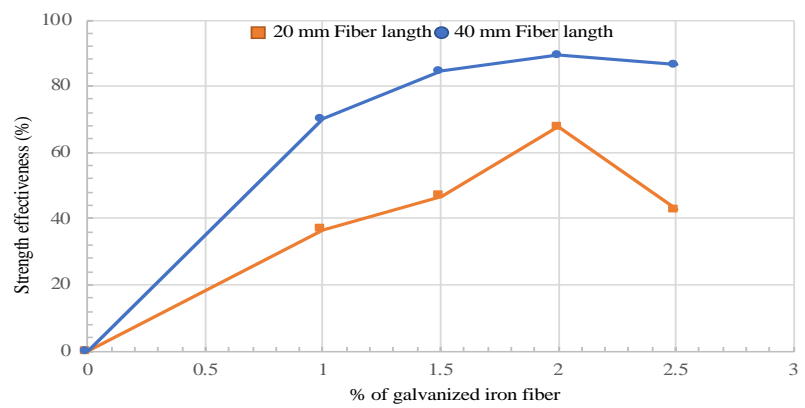

(d)

Figure 5. Change in concrete tension due to the fiber proportion in (a) $20 \mathrm{~mm}$ length (b) $40 \mathrm{~mm}$ length (c) comparison in the tension between $20 \mathrm{~mm}$ and $40 \mathrm{~mm}$ length (d) comparison with the strength increment between $20 \mathrm{~mm}$ and $40 \mathrm{~mm}$ length.

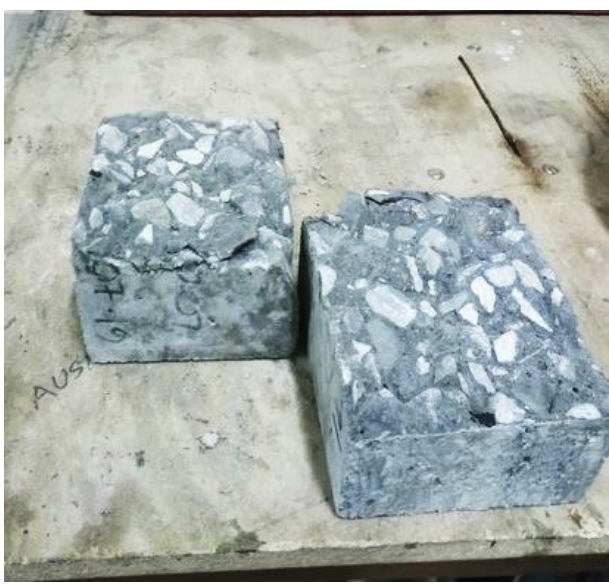

(a)

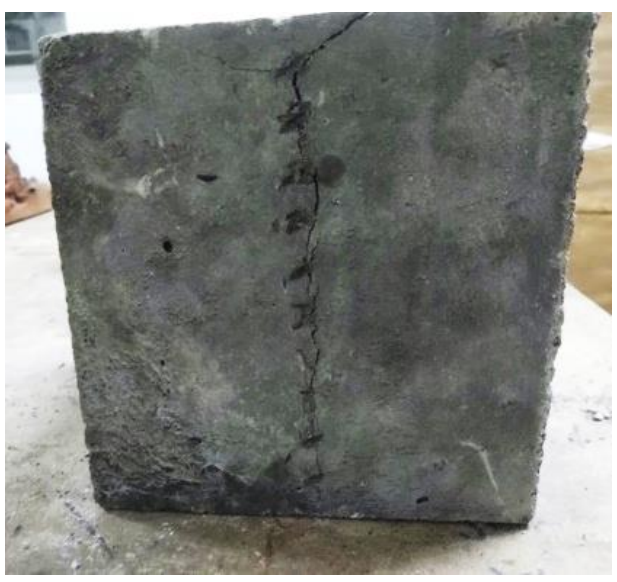

(b)

Figure 6. Concrete cube after the tension test (a) control Specimen (b) 1.5\% GIF.

The most effective result indicated by an $89.2 \%$ increment in the tension was found with a $2 \%$ mix proportion for $40 \mathrm{~mm}$ length. This means a lengthy fiber with averagely $\leq 2 \%$ of GI leads to the production of a concrete mixture which is able to withstand cracking under a tensile load as shown in Figure 6. Meanwhile, more proportion of GI fiber which is $>2 \%$ were found to have produced an incongruous mixture due to the deficiency caused by the free rearrangements of the concrete elements. The incorporation of $2.5 \%$ GI fiber was, however, discovered to have provided a superior contribution to tensile strength than the control specimen. Moreover, the previous research by Joshi et al [16] showed the possibility of enhancing concrete tension by adding steel fiber. This further confirms the ability of GI fiber to 
produce analogous effects when added to the concrete even though the increment of strength is a bit higher for SFRC.

\subsection{Influence of galvanized Iron fiber on concrete brittleness}

Concrete with high strength exhibits high friableness and this makes it important to appraise concrete performance, especially by using the ratio of tension to compression to determine its fragility (Li W, et.al. 2014 and Li. R, et.al. 2014) such that a higher ratio leads to lesser frailty. The results of the concrete brittleness due to the addition of galvanized iron are presented in Table 6 while the comparison based on the lengths is shown in Figure 7.

The most luminous difference between GI fiberreinforced and plain concretes is the characteristics of the failure. Figure 6 conspicuously shows brittle failure in the plain concrete as observed in it splitting into two pieces while ductile failure was found with GI fiber reinforced concrete which prevents it from splitting. Moreover, the fibers were also found to have aligned with the direction of the tension such that an increase in their proportion leads to a stable enhancement in the ratio of tension to compression. The use of galvanized iron fiber also reduced the frailty as observed with the $37.9 \%$ to $62.1 \%$ recorded for $20 \mathrm{~mm}$ length and $56.9 \%$ to $65.5 \%$ for $40 \mathrm{~mm}$ length compared to the control specimen. Furthermore, the GI fibers immure the crack by reinforcing the concrete whenever a fracture is originated. Those with high lengths were discovered to influence proper distribution due to their large specific area which increases the mechanical entanglement in the concrete. It is also important to note that the addition of a GIF with a 40 aspect ratio is much better to suppress brittleness than the 20 aspect ratio.

Table 6. Experimental outcomes of concrete brittleness

\begin{tabular}{l|lll}
\hline Type of Concrete & Fiber Content (\%) & Tensile to Compression Ratio & Reduction of Brittleness of Concrete (\%) \\
\hline Control Concrete & 0 & 0.058 & - \\
GIF1 & 1.0 & 0.080 & 37.9 \\
GIF2 & 1.5 & 0.084 & 44.8 \\
GIF3 & 2.0 & 0.094 & 62.1 \\
GIF4 & 2.5 & 0.082 & 41.3 \\
GIF5 & 1.0 & 0.091 & 56.9 \\
GIF6 & 1.5 & 0.0962 & 65.5 \\
GIF7 & 2.0 & 0.095 & 63.7 \\
GIF8 & 2.5 & 0.0956 & 64.8 \\
\hline
\end{tabular}

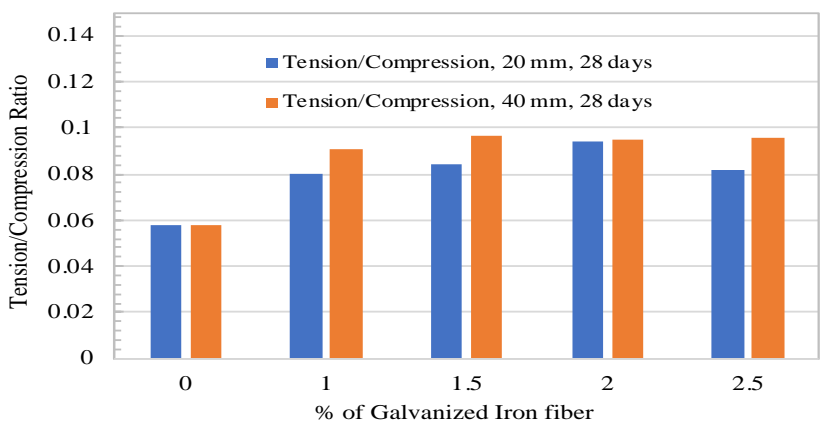

(a)

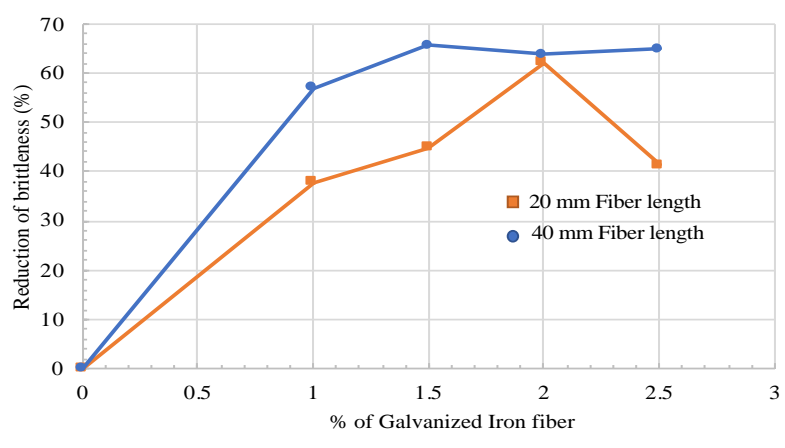

(b)

Figure 7. Change of concrete tensile/compression ratio with GI fiber proportion (a) Showing disparity of concrete brittleness between $20 \mathrm{~mm}$ and $40 \mathrm{~mm}$ length of galvanized iron (b) Showing disparity of concrete attenuation of brittleness between $20 \mathrm{~mm}$ and $40 \mathrm{~mm}$ length of galvanized iron. 


\section{CONCLUSION}

Laboratory experiments were conducted to determine the compression, tension, and brittleness of the concretes reinforced with 'Galvanized Iron' fiber. The results showed 20 $\mathrm{mm}$ length galvanized iron fiber was able to aggravate concrete compressive strength by $0.2 \%-3.5 \%$, increased tension by $36.6 \%-67.6 \%$, and reduced brittleness by $37.9 \%-62.1 \%$ while $40 \mathrm{~mm}$ length had $9.3 \%$ - 16.1\%, 70\% - 89.2\%, and $56.9 \%-65.5 \%$ respectively. The use of a 40 $\mathrm{mm}$ length for $2 \%$ GI fiber proportion was found to be the best mixture as observed in its effect on the compression with a $16.1 \%$ increase, tension with $89.2 \%$ increase, and brittleness with $63.7 \%$ crack reduction.

In comparison with steel fiber, the utilization of GI fiber showed a bit smaller enhancement in concrete compression and tension and has the potential to be used as a substitute for the expensive imported steel fiber in Bangladesh. This is due to the local availability of the GI fiber in the country which makes it a viable low-cost substitute in fiber reinforced concrete and its ability to improve the mechanical properties of concrete, especially the tension and brittleness.

\section{DISCLAIMER}

The authors declare no conflict of interest.

\section{ACKNOWLEDGMENTS}

The authors are grateful for the support provided by the laboratory furnished by the Ahsanullah University of Science \& Technology (AUST).

\section{REFERENCES}

ACI 211.1, 2009. Standard Practice for Selecting Proportions for Normal, Heavyweight and Mass Concrete. American Concrete Institute, Farmington Hills, MI, 48331-3439, USA.

ACI 224.1R, 2007. Causes, Evaluation, and Repair of Cracks in Concrete Structures. American Concrete Institute, Farmington Hills, MI, 483313439, USA.
American Galvanizers Association. ASTM Specifications. [Online] Available at: https://galvanizeit.org/specification-andinspection/coating-specifications/astmspecs\#ASTMmainstandards [Accessed 12 September 2019].

Darole, E. R. J. S., Kulkarni, V.P., Shaikh, A.P. and Gite, B.E., 2013. Effect of Hybrid Fiber on Mechanical Properties of Concrete. International Journal of Engineering Research and Applications (IJERA), 3, pp.1408-1411.

EN 12390-03, 2009. Testing Hardened Concrete, Part-3: Compressive Strength Test of Concrete. European Committee for Standardization, Avenue Marnix 17, B-1000 Brussels, Belgium.

EN 12390-06, 2000. Testing Hardened Concrete, Part-6: Tensile Splitting Test of Concrete. European Committee for Standardization, Avenue Marnix 17, B-1000 Brussels, Belgium.

Islam, G. M. S. and Gupta, S. D., 2016. Evaluating Plastic Shrinkage and Permeability of Polypropylene Fiber Reinforced Concrete. International Journal of Sustainable Built Environment, Elsevier, 5, pp.345-354.

Joshi A., Reddy, P, Kumar, P. and Hatker, P. 2016. Experimental Work on Steel Fibre Reinforced Concrete. International Journal of Scientific \& Engineering Research (IJSER), 7, pp.971-981.

Kim, J. S., Cho, C. G., Moon, H. J., Kim, H., Lee, S. J. and Kim, W., 2017. Experiments on Tensile and Shear Characteristics of Amorphous Micro Steel (AMS) Fibre-Reinforced Cementitious Composites. International Journal of Concrete Structures and Materials, 11, pp.647-655.

Li, R., Zhang, X. H. and Meng, Y. F., 2014. Study of Performance on Reduce Fragility and Increase the Toughness of Fly Ash Ceramsite Concrete. Advanced Materials Research, 997, pp.120-123.

Li, W., Huang, Z. and Wang, X. C., 2014. Study on Tension and Compression Ratio and Discount Ratio of Rubber Modified Silica Fume Concrete. Applied Mechanics and Materials, 670-671, pp. 396-400. 
Nemati, K. M., 2013. Fiber Reinforced Concrete (FRC). Concrete Technology, University of Washington.

Rouhi, J., Jamshidi, M. and Kakooei, S., 2011. The Effects of Polypropylene Fibers on the Properties of Reinforced Concrete Structures. Construction and Building Materials, 27, pp.2586-2481.

Sivakamasundari, S. and Balamurugan, S., 2019. Mechanical Properties of Hybrid Fiber Concrete. International Journal of innovative Technology and Exploring Engineering (IJITEE), 8, pp.146-150.
Sivakumar, A. and Santhanam, M., 2007. A Quantitative Study on the Plastic Shrinkage Cracking in High Strength Hybrid Fibre Reinforced Concrete. Cement Concrete Composite, 29, pp.575-581.

Vairagade, S. V. and Kene, S. K., 2013. Strength of Normal Concrete Using Metallic and Synthetic Fibers. Procedia Engineering, Elsevier, 51, pp.132140. 